\title{
Behavioral contrast in the pigeon depends upon the location of the stimulus*
}

\author{
BARRY SCHWARTZ \\ Swarthmore College, Swarthmore, Pennsylvania 19081
}

\begin{abstract}
Three pigeons were exposed to a series of multiple schedules of reinforcement-both multiple variable interval extinction, and multiple variable interval variable interval. The stimuli which signaled the two components of the multiple schedule were sometimes located on the response key, and sometimes removed from the key. Positive behavioral contrast (increases in variable-interval responding which accompany decreases in extinction responding) was only observed when the signal stimuli were on the response key. These findings are consistent with the view that positive contrast results from the introduction of a differential stimulus-reinforcer dependency which directs behavior toward the stimulus, as in the phenomenon of autoshaping.
\end{abstract}

The study of keypecking in pigeons has traditionally emphasized the influence of response-dependent reinforcement. However, recent research has indicated that keypecking is both established and maintained if a differential predictive relationship exists between response key illumination and food, even when food delivery is independent of responding (Brown \& Jenkins, 1968; Gamzu \& Schwartz, 1973; Gamzu \& Williams, 1971, 1973; Schwartz, 1973), or dependent on not responding (Schwartz \& Williams, 1972; Williams \& Williams, 1969). The powerful control of keypecking by a stimulus-reinforcer (keylight) dependency in the absence of a response-reinforcer dependency raises questions about the effects of stimulus-reinforcer and response-reinforcer dependencies in combination. One situation in which both types of dependency are present is the familiar multiple schedule procedure. A multiple schedule is one in which the component schedules are in force successively, each correlated with a different external stimulus. Thus, for example, in a multiple variable interval extinction schedule (mult VI-EXT), reinforcement depends upon both the keypeck and the presence of the stimulus which is correlated with the VI schedule.

One of the more striking phenomena observed with multiple schedules is positive behavioral contrast (e.g., Reynolds, 1961; Terrace, 1966). If a procedure is changed from mult VI-VI to mult VI-EXT, decreases in responding in the presence of the extinction stimulus are accompanied by increases in responding in the presence of the VI stimulus. Gamzu and Schwartz (1973) have recently suggested an explanation of behavioral contrast which depends upon independent contributions to the rate of keypecking by both stimulus-reinforcer and response-reinforcer dependencies. Consider the

*The research was supported by a grant from the Alfred $P$. Sloan Foundation to Swarthmore College. I am grateful to Daniel Reisberg and Teresa Vollmecke for their valuable assistance in the execution and analysis of the experiment. Reprints may be obtained from the author, Department of Psychology, Swarthmore College, Swarthmore, Pennsylvania 19081. mult VI-VI schedule. Here, the response-reinforcer dependency exerts control over keypecking. However, since both discriminative stimuli signal reinforcement availability, there is no differential stimulus-reinforcer dependency to also contribute to rate of pecking. When the schedule is changed to mult VI-EXT, the response-reinforcer dependency continues to maintain a given response rate in the presence of the VI stimulus. However, now there is also a differential stimulus-reinforcer dependency. Gamzu and Schwartz suggest that this dependency also maintains a given rate of pecking, and that the two rates simply combine. Thus, positive behavioral contrast is the result of summation of pecks which are separately controlled by stimulus-reinforcer and response-reinforcer dependencies. An experiment reported by Gamzu and Schwartz (1973) offers indirect support for this explanation of behavioral contrast. Pigeons were exposed to a series of multiple schedules of response-independent food presentation. When food was delivered at variable intervals averaging $33 \mathrm{sec}$ in one component, and not delivered in the other component, pecking was established and maintained in the presence of the food correlated stimulus. When food was delivered with the same frequency in both components, keypecking was substantially decreased. The pecking observed in this experiment was controlled by a differential stimulus-reinforcer dependency, as in mult VI-EXT schedules. It is precisely this keypecking which is presumed to sum with pecking maintained by a response-reinforcer dependency to produce what is called positive contrast.

A more direct test of this explanation of behavioral contrast is desirable, however. Schwartz (1973) has suggested that the reason why a differential stimulus-reinforcer dependency results in keypecking is that the stimulus is on the key, and that in general, behavior which is maintained by the relation between a stimulus and reinforcement will be directed to that stimulus (cf. Jenkins, 1973; Moore, 1973). The 
Table 1

Summary of Procedures

\begin{tabular}{lccc}
\hline & \multicolumn{2}{c}{ Stimulus } & \\
\cline { 2 - 3 } \multicolumn{1}{c}{ Procedure } & 1 & 2 & Sessions \\
\hline MULT VI1 VI1 & Red & Green & 12 \\
MULT EXT VI1 & Red & Green & 14 \\
MULT VI1 VI1 & Red & Green & 8 \\
MULT EXT VI1 & House- & House- & 8 \\
(Key Green) & light Off & light On & 8 \\
MULT VI1 VI1 & Red & Green & 7 \\
MULT EXT VI1 & Sona- & Sona- & 14 \\
(Key Green) & lert On & lert Off & 14 \\
MULT VI1 VI1 & Red & Green & 8 \\
MULT EXT VI1 & Red & Green & 14 \\
\hline
\end{tabular}

implication of the arguments of Gamzu and Schwartz (1973) and Schwartz (1973) is that the behavioral contrast occurs on multiple schedules only because the component schedules are signaled on the response key. If other stimuli were used to signal the different components of the multiple schedule, contrast would not be observed. The present experiment examined this possibility.

\section{METHOD}

\section{Subjects}

Three male Silver King pigeons that had served in previous experiments were maintained at $80 \%$ of free-feeding weight.

\section{Apparatus}

The center key of a three-key Lehigh Valley Pigeon Panel (Model No. LV1519C) could be illuminated with either red or green light. The feeder was located below the center key and the houselight was located above the key. A shield directed the light from the houselight toward the ceiling of the chamber. A sound source $(2,800 \mathrm{~Hz}$ Sonalert), in series with a $1,000-\mathrm{ohm}$ resistor, was located to the right of the feeder. During reinforcement, 4-sec access to mixed grain, a light in the feeder was illuminated and all other chamber lights were extinguished.

\section{Procedure}

The pigeons were exposed to a series of two-component multiple schedules of reinforcement. Each daily session consisted of 7250 -sec components with the two components of the multiple schedule alternated regularly. The initial procedure was a mult VI1-VI1 with the key alternately red and green. After 12 sessions, the schedule was changed to mult EXT-VI1 with EXT correlated with the red key, for 14 sessions. After 8 sessions of mult VI1-VI1, the mult EXt-VI1 procedure was reintroduced. This time, however, the key was always green. The VI was signaled by the illumination of the houselight, and EXT was signaled by the absence of houselight illumination. This procedure was in effect for 8 sessions, followed by a return to mult VI1-VI1, again signaled by key color. The mult EXT-VI1 schedule was then reintroduced, this time with the presence of the Sonalert correlated with EXT, and its absence correlated with VI. After 14 sessions, the mult VI1-VI1 schedule was reintroduced, followed by a return to mult EXT-VI1, again correlated with key color. After 85 total sessions, the experiment was terminated. The sequence of procedures is summarized in Table 1. It should be noted that absence of the houselight or presence of the Sonalert might have a direct suppressive effect on responding. For this reason, both of these stimulus conditions were correlated with EXT rather than VI.
Thus, the absence of behavioral contrast, if obtained, could not be attributed to the suppressive effects of the stimulus.

\section{RESULTS}

The dependent variable of primary interest in this experiment is the extent to which positive behavioral contrast occurs as a function of the stimulus which signals the VI component of the multiple schedule. The expectation was that contrast would occur only when key color signaled VI. The clearest way to assess the contrast effect is to normalize response rate. VI response rate during a mult EXT-VI procedure is divided by the mean response rate observed on the previous mult VI-VI procedure. Ratios greater than 1.0 indicate positive contrast. These normalized response rates are presented for each pigeon in Fig. 1. The panels are labeled by the stimulus which signaled VI. A number of sessions of mult VI-VI intervened between each pair of panels in the figure, but these data are not included. It is apparent from the first panel that large contrast effects were produced in each pigeon with the discriminative stimulus on the key. With the houselight as discriminative stimulus (second panel), there was no sign of contrast. When the Sonalert tone was the discriminative stimulus, Pigeon 4501 showed a clear, though small, contrast effect; for Pigeon 3880, the effect was, less clear; and for Pige on 4689, there was no contrast effect. Finally, when key color was again the discriminative stimulus, all three pigeons showed clear contrast.

Figure 2 presents session-to-session mean response rates on both VI and EXT for Pigeon 3880. The data for

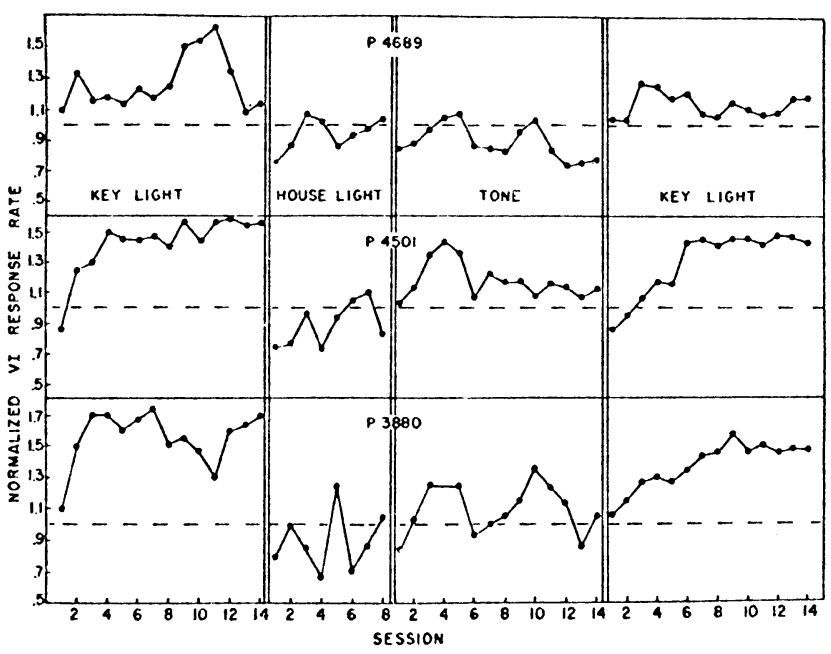

Fig. 1. Normalized VI response rates during MULT (EXT-VI) procedures are presented for each pigeon. Normalized rates are computed by dividing VI response rates during MULT (EXT-VI) by VI response rate during MULT (VI-VI). Each exposure to the MULT (EXT-VI) was preceded by a number of sessions of MULT (VI-VI), indicated by the double vertical lines. Each panel is identified by the stimulus which served as the discriminative cue during MULT (EXT-VI). The dashed horizontal lines indicate a normalized VI rate of 1.0. Points above these lines are evidence of positive behavioral contrast. 
the other two pigeons are comparable. The discrimination developed somewhat more slowly with the tone as the discriminative stimulus than with the houselight or the key, but responding in EXT reached roughly the same level in each case.

\section{DISCUSSION}

In this experiment, positive behavioral contrast occurred only when the stimulus which signaled the VI component of a mult VI-EXT schedule was located on the response key. These results are consistent with the view of behavioral contrast proposed by Gamzu and Schwartz (1973). That view may be summarized as follows: whenever a dependency exists between a response and a reinforcer, the reinforcer will maintain the response. Similarly, whenever a dependency exists between a stimulus and a reinforcer, the presentation of the stimulus will generate and maintain behavior. In the case of the pigeon, the behavior maintained by the stimulus-reinforcer dependency is pecking, and the pecks are directed at the stimulus (Brown \& Jenkins, 1968; Gamzu \& Williams, 1971; Schwartz, 1973; Staddon \& Simmelhag, 1971). As a result, with keypecking as the response in the response-reinforcer dependency, and the key as the stimulus in the stimulus-reinforcer dependency, these two sources of control of behavior sum, producing behavioral contrast. However, behavioral contrast is not an inevitable consequence of multiple schedule procedures. It depends on the procedural coincidence that both stimulus-reinforcer and response-reinforcer dependencies direct behavior toward the key. When the stimulus-reinforcer dependency does not serve this function, as in the present experiment, no contrast is observed. These results support and extend recent findings by Redford and Perkins (1974), with multiple schedules whose components were of unusually short duration.

Keller (1973) made similar observations with the response-reinforcer dependency and the stimulus-reinforcer dependency both directed behavior toward response keys, but toward different ones. Pecks on one key, the operant key, produced reinforcement according to a multiple schedule. However, the components of the multiple schedule were signaled on a second key. No contrast was observed on the operant key. However, on mult VI-EXT schedules, pecks were directed toward the VI stimulus on the signal key. The operant keypecks (response-reinforcer dependency), together with the signal keypecks (stimulus-reinforcer dependency) synthesized positive contrast.

The complementary agrument is that when the response-reinforcer dependency does not direct behavior toward the response key, no contrast will be observed. This has been confirmed empirically by Westbrook (1973), and Hemmes (1973). When treadle hopping is the operant, negative induction, rather than positive contrast occurs on multiple schedules. By present account, the behavior of treadle-hopping pigeons on multiple schedules and the behavior of barpressing rats on these schedules should be similar. Indeed, with rats as Ss, induction seems to be the rule, and contrast the exception (Pear \& Wilkie, 1971; Zimmerman \& Schuster, 1962; see Rachlin, 1973, for discussion). It should also be noted, however, that both Westbrook and Hemmes did observe some behavioral contrast when pecking was the response, but the signal was off the response key. Those findings contradict the bulk of the present results.

The present account of positive contrast, and its relation to other phenomena observed with complex schedules of reinforcement, has been amplified in an excellent theoretical discussion by Rachlin (1973). This account of contrast differs markedly from other accounts (Bloomfield, 1969; Freeman, 1971; Terrace, 1966) which have focused on possible emotional origins of the effect. The controversy has centered on whether

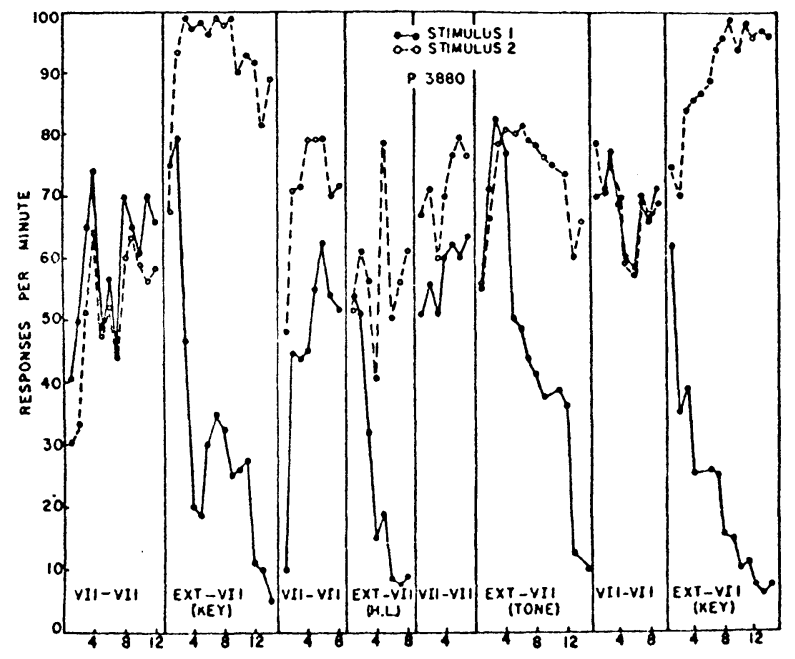

Fig. 2. Session-to-session mean response rates in both VI and EXT across all procedures are presented for one pigeon. Vertical lines indicate procedure changes, and each panel is labeled with the appropriate procedure.

the emotional effect of reduction in reinforcement rate of reduction in response rate is a necessary precondition for contrast (Freeman, 1971). The present discussion does not speak to this controversy. It is possible that reductions in either reinforcement rate or response rate are necessary precursors of behavioral contrast. What the present experiment indicates is that neither is sufficient. Procedures like the present one, which presumably produce the necessary em otional effects, only result in contrast when stimulus-reinforcer and response-reinforcer dependencies direct behavior to the same target.

\section{REFERENCES}

Bloom field, T. M. Behavioral contrast and the peak shift. In $R$ M. Gilbert and N. S. Sutherland (Eds.), A nimal discrimination learning. New York: Academic Press, 1969. Pp. 215-241.

Brown, P., \& Jenkins, H. M. Auto-shaping of the pigeon's key-peck. Journal of the Experimental Analysis of Behavior, $1968,11,1-9$.

Freeman, B. J. Behavioral contrast: Reinforcement frequency or response suppression? Psychological Bulletin, 1971, 75 347-356.

Gamzu, E., \& Schwartz, B. The maintenance of key pecking by stimulus-contingent and response-independent food presentation. Journal of the Experimental Analysis of Behavior, 1973, 19,65-72.

Gamzu, E., \& Williams, D. R. Classical conditioning of a complex skeletal act. Science, 1971, 171, 923-925.

Gamzu, E., \& Williams, D. R. Associative factors underlying the pigeon's key pecking in autoshaping procedures. Journal of the Experimental Analysis of Behavior, 1973, 19, 225-232.

Hemmes, $N$. Behavioral contrast in pigeons depends upon the operant. Journal of Comparative \& Physiological Psychology, $1973,85,171-178$.

Jenkins, H. M. Effects of the stimulus-reinforcer relation on selected and unselected responses. In R. A. Hinde and J. S. Hinde (Eds.), Constraints on learning. London: Academic Press, 1973. Pp. 189-203.

Keller, $\mathrm{K}$. The role of elicited responding in behavioral contrast. Unpublished Master's thesis, New York University, 1973.

Moore, B. R. The role of directed Pavlovian reactions in simple instrumental learning in the pigeon. In R. A. Hinde and J. S. Hinde (Eds.), Constraints on learning. London: Academic Press, 1973.

Pear, J. J.r \& Wilkie, D. M. Contrast and induction in rats on multiple schedules. Journal of the Experimental Analysis of Behavior, 1971, 15, 289-296.

Rachlin, H. Contrast and matching. Psychological Review, 1973, 80, 217-234.

Redford, M. E., \& Perkins, C. C. The role of autopecking in behavioral contrast. Journal of the Experimental Analysis of Behavior, 1974, 21, 145-150. 
Reynolds, G. S. Behavioral contrast. Journal of the Experimental Analysis of Behavior, 1961, 4, 57-71.

Schwartz, B. Maintenance of key pecking by response-independent food presentation: The role of the modality of the signal for food. Journal of the Experimental Analysis of Behavior, 1973, 20, 17-22.

Schwartz, B., \& Williams, D. R. Two different kinds of key-peck in the pigeon: Some properties of responses maintained by negative and positive response-reinforcer contingencies. Journal of the Experimental Analysis of Behavior, 1972, 18,

201-216.
Staddon, J. E. R., \& Simmelhag, V. L. The "superstition" experiment: A re-examination of its implications for the principles of adaptive behavior. Psychological Review, 1971, 78, 3-43.

Terrace, H. S. Stimulus control. In W. K. Honig (Ed.), Operant behavior: Areas of research and application. New York: Appleton-Century-Crofts, 1966. Pp. 271-344.

Westbrook R. F. Negative induction and inhibitory generalization gradients when foot-pressing $a$ bar is the response and the pigeon is the subject. Journal of the Experimental Analysis of Behavior, 1974, 21, in press.

Williams, D. R., \& Williams, H. Automaintenance in the pigeon: Sustained pecking despite contingent non-reinforcement. Journal of the Experimental Analysis of Behavior, 1969, 12, 511-520.

Zimmerman, J., \& Schuster, C. R. Spaced responding in multiple DRL schedules. Journal of the Experimental Analysis of Behavior, 1969, 5, 497-504.

(Received for publication March 2, 1974.)

\section{ERRATUM}

FUCCI, DONALD J., MCCAFFREY, PATRICK, CURTIS, ANN P., and BLACKMON, ROBERT. Oral vibrotactile stimulation: A study of practice effectBulletin of the Psychonomic Society, 1974, 3, 209-211Figure 1 on Page 210 has been published with the key reversed. The broken line should be the control group and the solid line should be the experimental group. 